\title{
Fractional Ablative Erbium: YAG Laser Resurfacing of Rhinophyma
}

\author{
MAI A. OSMAN, M.D. \\ Dermatology Unit, The Department of Medical Applications of Lasers, National Institute of Laser Enhanced Sciences (N.I.L.E.S), \\ Cairo University
}

\begin{abstract}
Background: Management of rhinophyma can be challenging. There are numerous approaches for treating rhinophyma. Fractional laser resurfacing has been recently proposed as a treatment modality for rhinophyma.

Aim of Study: To evaluate the efficacy and safety of fractional ablative 2,940-nm erbium: YAG laser in the treatment of rhinophyma.

Patients and Methods: Eight patients with mild to moderate rhinophyma received 4 successive monthly treatments with a fractional 2,940-nm erbium: YAG laser. Clinical assessment scores and patient satisfaction surveys were obtained at 3month follow-up. The final assessment took place at 6 months to detect recurrence.

Results: Cosmetic results were evaluated as excellent or very good in $75 \%$ of patients. Patient satisfaction scores paralleled the physician assessment scores. All of the patients tolerated the procedure well with healing time at 2-5 days. None of the patients had post-operative complications. One patient experienced recurrence.

Conclusion: Fractional ablative erbium: YAG laser is an efficient treatment alternative for patients with mild to moderate rhinophyma who are unable or unwilling to endure the prolonged post-operative recovery and the high incidence of adverse effects associated with ablative lasers and surgical procedures.
\end{abstract}

Key Words: Rhinophyma - Fractional erbium: YAG laserAcne rosacea.

\section{Introduction}

RHINOPHYMA was first recognized in ancient Greece and Arabia. In 1845, Von Hebra coined the word Rhinophyma [1]. He derived this word from the Greek word "rhis" meaning nose and "phyma" meaning growth [1]. Rhinophyma is a slowly progressive, benign, disfiguring disorder of the nose which presents the end stage of acne rosacea. The

Correspondence to: Dr. Mai A. Osman, Dermatology Unit, The Department of Medical Applications of Lasers, National Institute of Laser Enhanced Sciences (N.I.L.E.S), Cairo University clinical presentation includes an enlargement and hypervascularization of the lower two-thirds of the nose; in addition, a reddish purple discoloration develops, and the nose takes on a lobular, nodular appearance [2,3]. The most severe cases can affect breathing and even vision. Factors implicated in the worsening of rosacea and ultimately in the formation of rhinophyma have included Demodex folliculorum, alcohol, caffeine, spicy foods, and other vasodilatory agents [4-7]. Histopathologically, there is a chronic inflammatory process with hypertrophy of the subcutaneous and sebaceous tissues; the dilated ducts become occluded with inspissated debris, bacteria, and sebum [8]. Because rhinophy$\mathrm{ma}$ is a cosmetic disorder, it is expected to cause emotional distress if the symptoms are extensive or obvious enough. Patients seek medical aid to improve the shape of their disfigured noses [9] Treatment options range from topical antibiotics or isotretinoin (reserved for mild disease), surgical resection with or without subsequent skin graft, cryosurgery, electrocautery, dermabrasion and more recently laser therapy [10]. With the limitations of surgical techniques, lasers gained popularity for treating rhinophyma. However, laser ablation using conventional carbon dioxide ( $\left.\mathrm{CO}_{2}\right)$ and erbium yttrium aluminum garnet (Er:YAG) lasers are invasive and can lead to serious side effects and prolonged downtime [11,12]. Fractional Photothermolysis (FP) was introduced in an attempt to overcome the limitations posed by conventional ablative lasers. The fractionated lasers heat the tissue in columns called Microscopic Treatment Zones (MTZs). These surrounding areas of sparing act as reservoirs for healing, enabling the MTZs to resolve quickly with minimal discomfort by providing a reservoir for keratinocyte migration [13] The goal of this study was to evaluate and the efficacy and safety of fractional ablative $2,940 \mathrm{~nm}$ Er:YAG laser for the treatment of mild to moderate rhinophyma. 


\section{Patients and Methods}

This study was conducted in the Outpatient Dermatology Clinic at the National Institute of Laser Enhanced Sciences, Cairo University from July 2017 to June 2018. Informed consent was obtained from all the patients before enrollment, and they gave written and signed permission to use all data and photographs for scientific aims. This clinical study was conducted in accordance with the Helsinki Declaration of 1975. Eight patients ( 5 males and 3 females), aged 45-71 years (mean 57.75 years) with Fitzpatrick skin phototypes III to IV having mild to moderate rhinophyma were treated with fractional ablative 2,940-nm Er:YAG laser. The diagnosis of rhinophyma was made clinically and the severity of the nasal deformity was assessed using the grading system devised by El-Azhary and colleagues [10]. The duration of rhinophyma ranged from 2 to 15 years (mean 6.5 years). All patients had been receiving medical treatment for acne rosacea for several years before the procedure, and the rosacea was inactive at the time of laser therapy.

\section{Technique:}

The nose was prepared and the area to be treated was marked. Patients were anesthetized topically with 5\% lidocaine cream to reduce pain or discomfort. All appropriate laser precautions were taken prior to starting treatment. Protective eyewear was worn by the patient and all present in the room throughout the treatment.

Erbium: YAG laser (Fotona Xs Dynamics, Slovenia) was used. The parameters applied were: fluence 250 to $300 \mathrm{~mJ}, 30$ to $40 \mathrm{~mm}$ ablation depth, handpiece PSO1, spot size $7 \mathrm{~mm}$ in diameter, MTZ density level of 2 to 3 , Short Pulse (SP) duration mode, and frequency 6 to $8 \mathrm{~Hz}$. The Erbium: YAG laser which allows tissue vaporization, was used with a back and forth motion on the diseased tissue The resurfacing was continued in the prominent sebaceous areas with up to 10 passes while the less sebaceous areas of the nose were treated with fewer passes. There was continuous vacuum suctioning of the smoke during the procedure. No forced air cooling was used.

At the end of the treatment, a vaseline occlusive dressing with antibiotic ointment was then placed. Patients were given wound care instructions, including daily application of an antibiotic cream (fusidic acid) for the first week after treatment and a broad-spectrum sunscreen until reepithelialization was complete. The patients did not require additional medications for pain management. All pa- tients received 4 laser treatments with 4 -week intervals between the sessions and followed-up over the next 3 months. An additional follow-up appointment at 3 months (6 months after the last session) was arranged to detect any signs of recurrence.

Sequential photographs were taken before and after treatment ( 3 months after the final treatment) to assess the outcome of the treatment using a fourlevel scale. This scale incorporates the subjective response of the patient with the objective observations of the physician as follows: (1) Excellent result, the patient is very satisfied with the cosmetic effect. (2) Very good result, the patient is satisfied with the cosmetic effect. (3) Good result, the patient is neutral. (4) Poor result, the patient is unsatisfied with the cosmetic effect. Any side effects observed were recorded at each treatment session and during the follow-up period ( 3 months after the last session).

\section{Statistical analysis:}

Statistical analysis was performed using statistical software program SPSS (V.24.0, IBM Corp., USA, 2016). Quantitative data were expressed as mean, standard deviation and medians with ranges, whereas qualitative data were expressed as frequency (count) and relative frequency (percentage).

\section{Results}

A total of 8 patients with a mean age of 57.75 years (range: 45-71 years) were considered for this study. Based on the clinical classification by ElAzhary et al., 4 patients had mild and 4 had moderate rhinophyma (Table 1).

Table (1): Patient characteristics.

\begin{tabular}{ll}
\hline Characteristic & \multicolumn{1}{c}{ Value } \\
\hline Age (range, mean), years & $(45-71) 57.75$ \\
Sex, $n(\%):$ & \\
• Female & $3(37.5 \%)$ \\
• Male & $5(62.5 \%)$ \\
Fitzpatrick skin phototype, $n(\%):$ & \\
• III & $6(75 \%)$ \\
• IV & $2(25 \%)$ \\
Rhinophyma severity, $n(\%):$ & \\
• Mild & $4(50 \%)$ \\
• Moderate & $4(50 \%)$ \\
• Duration of rhinophyma (range, mean), & $(2-15) 6.5$ \\
$\quad$ years & \\
\hline
\end{tabular}

At 3-month follow-up, among the 8 patients studied, 4 achieved an excellent result (50\%), 2 very good $(25 \%)$ and 2 good $(25 \%)$, with no poor result. Clinically, good nasal contour, color and alar symmetry were achieved in all cases Fig. (1). 

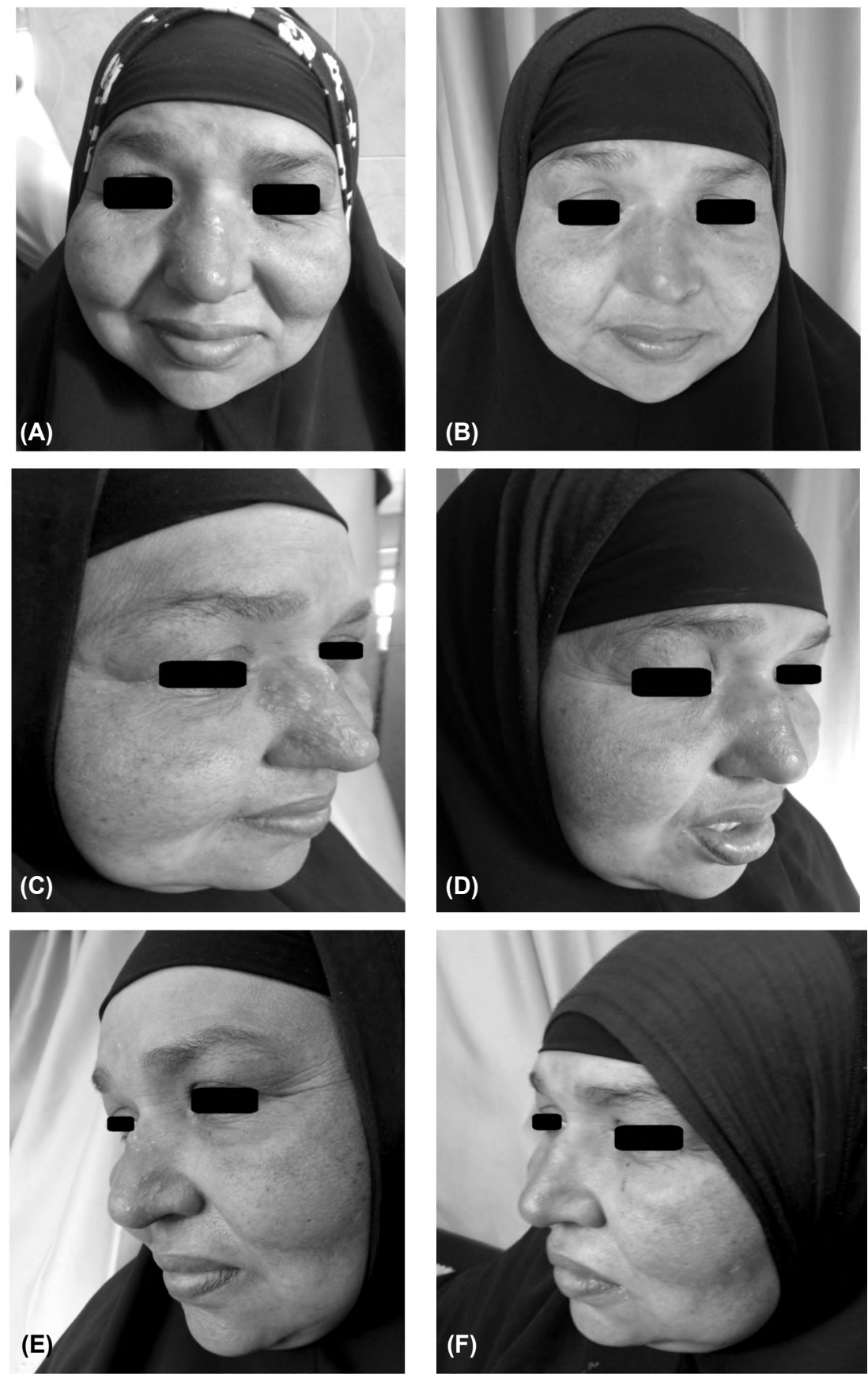

Fig. (1): A 47-year-old female patient with mild rhinophyma. (A) Before treatment frontal view, (B) After 4 fractional erbium: YAG laser treatments frontal view, (C) Before treatment right lateral view, (D) After treatment right lateral view, (E) Before treatment left lateral view, (F) After treatment left lateral view.

Half of the patients $(4 / 8)$ were very satisfied with the laser treatment, 2 were satisfied and 2 were neutral. The majority of patients $(75 \%)$ were very pleased with the final cosmetic results and were willing to recommend this procedure to other patients with rhinophyma. The beneficial effects of farctional erbium: YAG laser treatment were not limited to cosmetic outcome as most patients reported improved confidence and well being and attended the return consultation with apparently higher self-esteem.
Reepithelialization took an average of 3.7 days (2-5 days). All patients tolerated the treatment well under topical anesthesia alone. In all patients, side effects were mild to moderate and consisted of erythema, crusting, and swelling that lasted for a few days. No persistent side effects such as hyperor hypopigmentation or scarring were observed in any of the treated patients at follow-up.

Only one patient experienced a recurrence of the condition in the 6-month follow-up period and 
will be submitted to another treatment session (Table 2).

Table (2): Data summary of treatment outcome.

\begin{tabular}{ll}
\hline Data & Value \\
\hline Cosmetic result (n, \%): & \\
Excellent & $4(50 \%)$ \\
Very good & $2(25 \%)$ \\
Good & $2(25 \%)$ \\
Poor & $0(0 \%)$ \\
Patient satisfaction (n, \%): & \\
Very satisfied & $4(50 \%)$ \\
Satisfied & $2(25 \%)$ \\
Neutral & $2(25 \%)$ \\
Unsatisfied & $0(0 \%)$ \\
Re-epithelialization (range, mean), days & $(2-5) 3.7$ \\
Recurrence (n,\%) & $1(12.5 \%)$ \\
\hline
\end{tabular}

\section{Discussion}

Rhinophyma can be a social stigma that prompts patients to seek treatment for this cosmetic problem. It also causes functional problems including obstruction of the nares (one or both) and difficulty in breathing. Rhinophyma remains a troublesome condition for which no single effective treatment exists [14]

The carbon dioxide laser was first reported in 1980 for the treatment of rhinophyma [12]. In recent years, Er:YAG lasers have been increasingly reported in the literature [15-17]. The Erbium:YAG laser is a solid state laser which emits a wavelength of $2940 \mathrm{~nm}$ in the mid-infrared region. This wavelength is the peak of light absorption in water which makes the Er:YAG an effective soft tissue ablative surgical device. It offers an excellent solution for careful ablative removal of superficial layers with maximum sparing of adjacent tissue structures. Er:YAG laser absorption in water is tenfold higher than that of the $\mathrm{CO} 2$ laser. Thus, the heat produced by the absorption of the Er:YAG is efficiently used for tissue ablation, with very little heat conduction to surrounding tissue. The $\mathrm{CO}_{2}$ laser, with its higher heat conduction will cause deep thermal damage to the neighboring tissue resulting in longer healing time and higher incidence of complications compared to Er:YAG laser $[18,19]$.

Hantash et al., [20] first published results with an ablative fractional resurfacing device in 2007. The delivery of energy in columns with surrounding zones of uninjured tissue promotes rapid wound healing and collagen induction resulting in contraction and tightening of the tissue [13,21]. There is decreased risk of scarring and shorter downtime than seen with traditional ablative treatments, as the uninjured skin allows for faster reepithelialization. This might interpret the absence of postoperative complications in the present study.

This study provides further evidence of the effectiveness of the fractional ablative resurfacing for treatment of rhinophyma and is the first study, to our knowledge, to demonstrate the efficacy of fractional erbium: YAG laser in the treatment of rhinophyma. Here we present eight cases of mild to moderate rhinophyma that were successfully treated with fractional erbium: YAG laser.

The small proportion of female patients with rhinophyma in our study ( 3 women and 5 men) is consistent with the results published by several authors $[22,23]$. Compared with men, women had less severe disease, and presented early for treatment. Also, the age distribution of this study is comparable to those reported in previous studies [24-26]

Overall, the outcome with this technique was excellent to very good in $75 \%$ of the treated cases at 3-month follow-up. Most of the patients stated that they were very satisfied or satisfied with the cosmetic result. Furthermore, the majority of patients of our study would recommend this treatment modality to other affected patients. This statement serves as an additional surrogate marker for the overall patient satisfaction. These findings are consistent with those of Serwoka et al., [27] who treated 5 patients with long standing history of mild to moderate rhinophyma with a series of fractional ablative $\mathrm{CO} 2$ laser treatments. They noted significant improvement and reduction in the rhinophyma without the typical scarring noted with most other treatments.

Similarly, Meesters et al., [28] conducted a study on three patients with mild rhinophyma who were treated with a fractionated carbon dioxide $\left(\mathrm{CO}_{2}\right)$ laser. Two patients experienced significant improvement, whereas one patient showed little response.

Orenstein et al., [29] reported marked cosmetic improvement in 6 patients with moderate to severe rhinophyma after a single ablative Er:YAG laser treatment with no complications. However, the post-operative healing time was seven to fourteen days, significantly longer than that in our study. Ablative lasers work by creating homogenous thermal damage at a specified depth within the skin [12]. These lasers have generally fallen out of favor due to their high side effect profile which limit its usefulness and prolonged healing time 
which is often inconvenient for patients, especially those with only mild disease [13].

It should be noted that the variation in the parameters used and in the number of passes applied for different aspects of the nose in the current study, created a more natural result that can be feathered at the edges of the treatment resulting in a blended natural appearance.

In the present study, one case of recurrence was observed. Optimal cosmetic results can be achieved by careful removal of hyperplastic sebaceous tissue with preservation of the deepest portion of adnexal structures to guarantee scar-free re-epithelialization. For this reason, recurrence of rhinophyma is a well-known phenomenon, particularly when hyperplastic tissue is not removed completely [30]

Limitations in this study might include a small sample size and the lack of histopathological examination to rule out the presence of a co-existent pathology.

\section{Conclusion:}

In conclusion, the fractional Er:YAG laser is effective for treatment of mild to moderate rhinophyma with a pain-free rapid postoperative recovery and an excellent safety profile compared with conventional surgical procedures and ablative lasers. However, it may not be the ideal resurfacing tool for severe rhinophyma or patients with bulky lesions. Further research is needed in order to confirm these preliminary findings and to optimize laser settings and number of treatment sessions. Besides, as public demand grows for less invasive modalities to treat common cosmetic skin concerns, dermatologic surgeons must continue to explore new treatment options.

\section{References}

1- ROBERTS J.O. and WARD C.M.: Rhinophyma. J. R. Soc. Med., 78 (8): 678-81, 1985.

2- NELSON B. and FUCIARELLI K.: Surgical management of rhinophyma. Cutis, 61 (6): 313-6, 1998.

3- HOASJOE D.K. and STUCKER F.J.: Rhinophyma: Review of pathophysiology and treatment. J. Otolaryngol., 24 (1): 51-6, 1995.

4- WIEMER D.R.: Rhinophyma. Clin. Plast. Surg., 14 (2): 357-65, 1987.

5- DOTZ W. and BERLINER N.: Rhinophyma. A master's depiction, a patron's affliction. Am. J. Dermatopathol., 6 (3): 231-5, 1984.

6- ROHRICH R.J., GRIFFIN J.R. and ADAMS W.P. Jr.: Rhinophyma: Review and update. Plast. Reconstr. Surg., 110 (3): 860-9; quiz 870, 2002.
7- AYERS S. Jr., et al.: Demodex folliculorum in rosacea. Arch. Dermatol., 101 (6): 706-7, 1970.

8- ARIKAN O.K., MULUK N.B. and CIRPAR O.: Treatment of rhinophyma with radiofrequency: A case report. BENT, 6 (3): 209-13, 2010.

9- SIMO R. and SHARMA V.L.: Treatment of rhinophyma with carbone dioxide laser. J. Laryngol. Otol., 110: 8416, 1996.

10- EL-AZHARY R.A., ROENIGK R.K. and WANG T.D.: Spectrum of results after treatment of rhinophyma with the carbon dioxide laser. Mayo Clin. Proc., 66: 899-905, 1991.

11- SADICK H., GOEPEL B., BERSCH C., GOESSLER U., HOERMANN K. and RIEDEL F.: Rhinophyma: Diagnosis and treatment options for a disfiguring tumor of the nose. Ann. Plast. Surg., 61: 114-20, 2008.

12- SHAPSHAY S.M., STRONG M.S., ANASTASI G.W. and VAUGHAN C.W.: Removal of rhinophyma with the carbon dioxide laser: A preliminary report. Arch. Otolaryngol., 106 (5): 257-9, 1980.

13- MANSTEIN D., et al.: Fractional photothermolysis: A new concept for cutaneous remodeling using microscopic patterns of thermal injury. Lasers Surg. Med., 34 (5): 42638, 2004.

14- VOJINOVIC'M., BILIC'M., KOVAC L., PER CICVOJINOVIC' S. and BASTA-JUZBA CIC' A.: Treatment of Massive Rhinophyma by Combined Electrosurgery and $\mathrm{CO} 2$ Laser. Acta Dermatovenerol. Croat., 17 (1): 20 4, 2009.

15- FINCHER E.F. and GLADSTONE H.B.: Use of a dualmode erbium: YAG laser for the surgical correction of rhinophyma. Arch. Facial. Plast. Surg., 6: 267-71, 2004.

16- GOON P.K., DALAL M. and PEART F.C.: The gold standard for decortications of rhinophyma: Combined erbium-YAG/CO 2 laser. Aesthetic Plast. Surg., 28: 45660, 2004.

17- TRELLES M.A.: Laser resurfacing today and the 'cook book' approach: A recipe for disaster? J. Cosmet. Dermatol., 3: 237-41, 2004.

18-RIZOIU I.M., EVERSOLE L.R. and KIMMEL A.I.: Effect of an erbium, Chromium: Yttrium, scandium, gallium, garnet laser on mucocutaneous soft tissues. Oral. Surg. Oral. Med. Oral. Radio Endod., 82: 386-95, 1996.

19- KAUFMANN R., HARTMANN A. and HIBST R.: Cutting and skin ablative properties of pulsed mid infrared laser surgery. J. Dermatol. Surg. Oncol., 20: 112-8, 1994.

20- HANTASH B.M., et al.: In vivo histological evaluation of a novel ablative fractional resurfacing device. Lasers Surg. Med., 39 (2): 96-107, 2007.

21- LAUBACH H.J., et al.: Skin responses to fractional photothermolysis. Lasers Surg. Med., 38 (2): 142-9, 2006.

22- WOLLINA U.: Rosacea and rhinophyma in the elderly. Clin. Dermatol., 29 (1): 61-8, 2011.

23- LITTLE S.C., STUCKER F.J., COMPTON A. and PARK S.S.: Nuances in the management of rhino-phyma. Facial Plast. Surg., 28 (2): 231-7, 2012.

24- WETZIG T., AVERBECK M., SIMON J.C. and KENDLER M.: New rhinophyma severity index and mid-term results 
following shave excision of rhinophyma. Dermatology, 227: 31-6, 2013.

25- LAZZERI D., LARCHER L., HUEMER G.M., et al.: Surgical correction of rhinophyma: Comparison of two methods in a 15-year-long experience. J. Craniomaxillofac. Surg., 41: 429-36, 2013.

26- BIENIEK A., MATUSIAK L., CHLEBICKA I. and SZEPIETOWSKI J.C.: Secondary intention healing in skin surgery: Our own experience and expanded indications in hidradenitis suppurativa, rhinophyma and nonmelanoma skin cancers. J. Eur. Acad. Dermatol. Venereol., 27: 1015-21, 2013.

27- SEROWKA K.L., SAEDI N., DOVER J.S. and ZACHARY C.B.: Fractionated Ablative Carbon Dioxide Laser for the Treatment of Rhinophyma. Lasers in Surgery and Medicine, 46: 8-12, 2014.

28- MEESTERS A.A., LINDEN M.M., De RIE M.A. and WOLKERSTORFER A.: Fractionated carbon dioxide laser therapy as treatment of mild rhinophyma: Report of three cases. Dermatologic Therapy, 28: 147-50, 2015.

29- ORENSTEIN A., HAIK J., TAMIR J., WINKLER E., FRAND J., ZILINSKY I. and KAPLAN H.: Treatment of Rhinophyma with ER:YAG Laser. Lasers in Surgery and Medicine, 29: 230-5, 2001.

30- SCHWEINZER K., KOFLER L., SPOTT C., KRUG M., SCHULZ C., SCHNABL S.M., et al.: Surgical treatment of rhinophyma: Experience from a German cohort of 70 patients. Eur. J. Dermatol., 27 (3): 281-5, 2017.

\section{تآثير ليزر الآربيوم ياج المجزآ فى علاج تضخم الغدد الدهنية بالآثف}

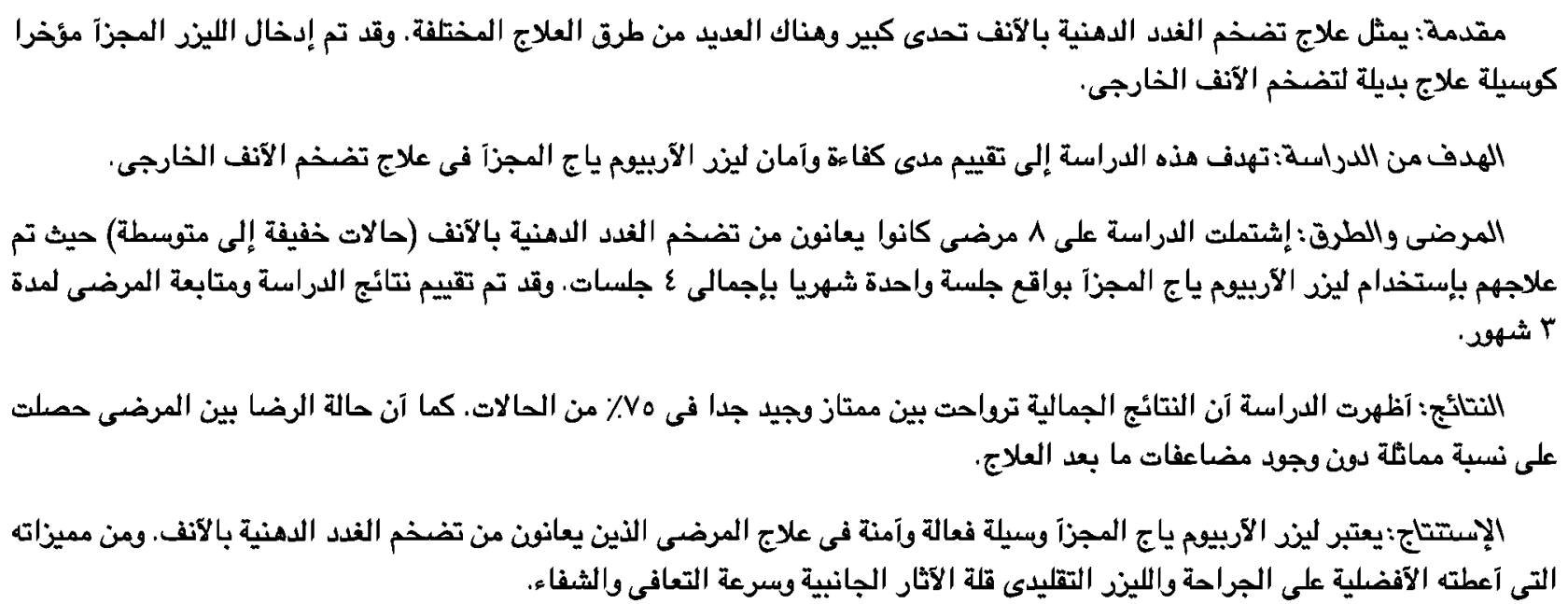

